\title{
Aeration simulation of stored grain under variable air ambient conditions
}

\author{
Daniela de Carvalho Lopes ${ }^{\mathrm{a}, *}$, José Helvecio Martins ${ }^{\mathrm{a}}$, Evandro de Castro Melo ${ }^{\mathrm{a}}$, \\ Paulo Marcos de Barros Monteiro ${ }^{b}$ \\ ${ }^{a}$ Federal University of Viçosa, Department of Agricultural Engineering, Av. P.H. Rolfs, s/n, Campus Universitário, Viçosa, 36570-000 MG, Brazil \\ ${ }^{\mathrm{b}}$ Federal University of Ouro Preto, Department of Control and Automation, Escola de Minas, Campus Universitário, \\ Morro do Cruzeiro, Ouro Preto, 35400-000 MG, Brazil
}

Received 9 January 2006; accepted 10 May 2006

\begin{abstract}
A simulation model for stored grain aeration was implemented and compared with experimental data. The software, called AERO, is capable of simulating the aeration process in stored grain, with hot spots, using time variant ambient data. Some modifications to the original model proposed by Thorpe [Thorpe, G.R., 1997. Modelling ecosystems in ventilated conical bottomed farm grain silos. Ecol. Modell. 94, 255-286] have been presented. The modified model is simpler, less computer-intensive and maintains the accuracy of the results. Comparing the model with data collected between January and August 2005, it was observed that the simulation results agreed well with real conditions, indicating that this software can reliably predict the aeration process for different world regions.
\end{abstract}

(C) 2006 Elsevier B.V. All rights reserved.

Keywords: Aeration; Grain; Simulation

\section{Introduction}

Simulation models can be used to predict temperature, dry matter loss and moisture content of stored grain. Generally, these models are used to evaluate the efficacy of ambient air ventilation, to estimate the maximum safe storage period of grain and to predict the necessary aeration time. With these evaluations, it is possible to analyze the aeration viability for a specific region and to optimize control strategies. The value of the simulation is greater in tropical and subtropical regions, where the aeration benefits have not been totally investigated, experimentally.

Many mathematical models have been developed to simulate the heat and the mass transfers in aerated bulk stored grains (Andrade, 2001; Canchun et al., 2001; Devilla, 2002; Sinício et al., 1997; Thorpe, 1997; Wilson, 1988). Many studies have also been conducted to predict the temperature and moisture content variation in stored grain without aeration (Alagusundaran et al., 1990; Davidson, 1986; Muir et al., 1980; Sinício et al., 1997; Thorpe and Elder, 1982; White,

\footnotetext{
* Corresponding author. Tel.: +55 $3138915909 / 99131597$.

E-mail address: danielaclopes@gmail.com (D. de Carvalho Lopes).
}

1988). Generally, these models are based on energy and mass balances. In some cases, it is also possible to estimate the airflow velocity, the airflow distribution and the pressure variation inside the bin. In these studies, the authors obtained reliable results, but it is clear that further research is required.

Recent advances in computer technology enabled the development of general-purpose software programs to simulate grain aeration, which can be used in sensitivity analysis, relating the main variables involved in this process and help to manage this technology.

The objective of this work was to present the methodology employed in the development of a software program, called AERO, that simulates the grain aeration process based on a one-dimensional model by using time variant ambient data, which enables the effects of hot spots to be considered.

\section{Methodology}

The mathematical model used in this work was based on that formulated by Thorpe (1997) and presented in more detail by Thorpe (2001). This model relates air psychometric relationships with mass and energy balances. Some changes 
were made in the original equations in order to simplify it, decreasing its execution time, but without decreasing its accuracy. The differential equations that describe the heat and mass transfer in an aerated bulk of grain are expressed as:

$$
\begin{gathered}
\frac{\partial \theta}{\partial t}\left\{\rho_{\mathrm{b}}\left[c_{\mathrm{g}}+c_{\mathrm{w}}^{U}\right]+\varepsilon \rho_{\mathrm{a}}\left[c_{\mathrm{a}}+R\left(c_{\mathrm{w}}+\frac{\partial h_{\mathrm{v}}}{\partial T_{\mathrm{a}}}\right)\right]\right\} \\
=\rho_{\mathrm{b}} h_{\mathrm{s}} \frac{\partial U}{\partial t}-u_{\mathrm{a}} \rho_{\mathrm{a}}\left[c_{\mathrm{a}}+R\left(c_{\mathrm{w}}+\frac{\partial h_{\mathrm{v}}}{\partial T_{\mathrm{a}}}\right)\right] \frac{\partial \theta}{\partial y} \\
+\rho_{\mathrm{b}} \frac{\mathrm{d} m_{\mathrm{s}}}{\mathrm{d} t}\left(Q_{\mathrm{r}}-0.6 h_{\mathrm{v}}\right)
\end{gathered}
$$

$\frac{\partial U}{\partial t} \rho_{\mathrm{b}}=-\rho_{\mathrm{a}} u_{\mathrm{a}} \frac{\partial R}{\partial y}+\frac{\mathrm{d} m_{\mathrm{s}}}{\mathrm{d} t}(0.6+U)$

where $c_{\mathrm{a}}$ is the specific heat of air $\left(\mathrm{J} \mathrm{kg}^{-1}{ }^{\circ} \mathrm{C}^{-1}\right), c_{\mathrm{g}}$ the specific heat of dry grain $\left(\mathrm{J} \mathrm{kg}^{-1}{ }^{\circ} \mathrm{C}^{-1}\right), c_{\mathrm{w}}$ specific heat of water $\left(\mathrm{J} \mathrm{kg}^{-1}{ }^{\circ} \mathrm{C}^{-1}\right), h_{\mathrm{v}}$ the latent heat of vaporization of water $\left(\mathrm{J} \mathrm{kg}^{-1}\right), h_{\mathrm{s}}$ the differential heat of sorption $\left(\mathrm{J} \mathrm{kg}^{-1}\right), U$ the grain moisture content $(\%)$ on a dry basis, $m_{\mathrm{s}}$ the grain's dry matter loss (\%), $Q_{\mathrm{r}}$ the heat of oxidation of grain $\left(\mathrm{J} \mathrm{s}^{-1} \mathrm{~m}^{-3}\right)$, $T_{\mathrm{a}}$ the air temperature in equilibrium with the grain $\left({ }^{\circ} \mathrm{C}\right), t$ the time $(s), u_{\mathrm{a}}$ the aeration air velocity $\left(\mathrm{m} \mathrm{s}^{-1}\right), R$ the humidity ratio of air $\left(\mathrm{kg} \mathrm{kg}^{-1}\right), y$ the vertical coordinate $(\mathrm{m}), \varepsilon$ the grain porosity (decimal), $\rho_{\mathrm{a}}$ the density of intergranular air $\left(\mathrm{kg} \mathrm{m}^{-3}\right), \rho_{\mathrm{b}}$ the bulk density of the grain $\left(\mathrm{kg} \mathrm{m}^{-3}\right)$ and $\theta$ is the grain temperature $\left({ }^{\circ} \mathrm{C}\right)$.

In this work, the partial differential equations that describe heat and mass transfer, in bulk stored grains, were solved using numerical analysis (Eqs. (3) and (4)) because the solution of one affects the solution of the other and because the temperature and the relative humidity of the aeration air vary arbitrarily with time (Navarro and Noyes, 2001).

$$
\begin{aligned}
\theta_{i \text { new }}= & \theta_{i}+\frac{\Delta t}{\rho_{\mathrm{b}}\left(c_{\mathrm{g}}+c_{\mathrm{w}}\right)+\varepsilon \rho_{\mathrm{a}}\left[c_{\mathrm{a}}+R_{i}\left(c_{\mathrm{w}}+\mathrm{d} h_{\mathrm{v}}\right)\right]} \\
& \times\left(h_{\mathrm{s}}\left(-\rho_{\mathrm{a}} u_{\mathrm{a}}\left(\frac{R_{i}-R_{i-1}}{\Delta y}\right)+\mathrm{d} m\left(0.6+U_{i}\right)\right)\right. \\
& +\rho_{\mathrm{b}} \mathrm{d} m\left(Q_{\mathrm{r}}-0.6 h_{\mathrm{v}}\right)-u_{\mathrm{a}} \rho_{\mathrm{a}}\left(c_{\mathrm{a}}+R_{i}\left(c_{\mathrm{w}}+\mathrm{d} h_{\mathrm{v}}\right)\right) \\
& \left.\times\left(\frac{\theta_{i}-\theta_{i-1}}{\Delta y}\right)\right)
\end{aligned}
$$$$
U_{i \text { new }}=U_{i}+\frac{\Delta t}{\rho_{\mathrm{b}}}\left(-\rho_{\mathrm{a}} u_{\mathrm{a}}\left(\frac{R_{i}-R_{i-1}}{\Delta y}\right)+\mathrm{d} m \mathrm{~d} t\left(0.6+U_{i}\right)\right)
$$

where $i$ denotes the node under consideration, $\mathrm{d} h_{\mathrm{v}} \mathrm{d} T_{\mathrm{a}}$ is the differential of latent heat with relation to temperature, $\mathrm{d} m \mathrm{~d} t$ is the rate of dry matter loss, $\Delta t$ the time interval (s) and $\Delta y$ is the section length $(\mathrm{m})$.

The bulk of grains was divided into sections in the vertical direction (direction of the airflow), as shown in Fig. 1. The section limits were called nodes and at the first node it was assumed that the mass and temperature steady state

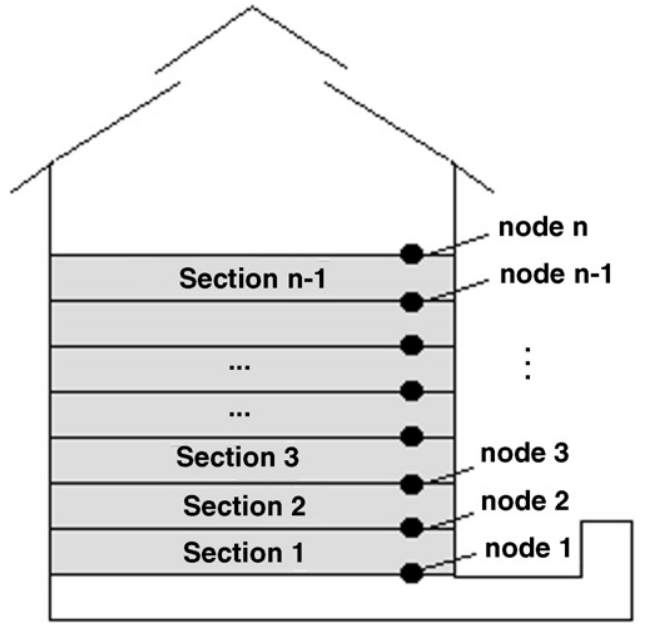

Fig. 1. Scheme used to characterize the various sections of a stored grain bulk.

conditions existed between equilibrium between the aeration air and surface of the bulk of grain. This configuration tends to overestimate the moisture content value of the first grain section. But, this problem was minimized by estimating the temperature and the moisture content of the first section using a Lagrangian interpolation considering the first four nodes.

Each section length was obtained by dividing the height of the grain bulk $(L)$ by the total sections number $\left(N_{S}\right)$. The software user should provide, as input data, the initial distribution of grain moisture content and temperature, the type of stored grain, its bulk density (the user can consult values registered in a database), the number of sections, the bin diameter and length, the local barometric pressure, the required airflow rate and the name of the file that contains the ambient data and the air temperature rise due to the fan operation. The initial distributions of grain moisture content and temperature can be uniform or contain hot spots and sections with different moisture contents.

During the simulation process, the grain moisture content and temperatures are calculated after each time interval for each section in an iterative way.

In the original mathematical model, the specific heat of dry grain, the specific heat of air and the specific heat of water were considered as constants. Navarro and Noyes (2001) pointed out that the specific heat of water and the specific heat of air are well-established quantities and in this work they were also used as constant values $\left(4186\right.$ and $1000 \mathrm{~J}^{\circ} \mathrm{C} \mathrm{kg}^{-1}$, respectively). But Brooker et al. (1992) reported that the specific heat of grain changes according to the grain moisture content variation. So, in the simulation executed by AERO, this parameter is calculated in each time interval for each grain section using Eq. (5):

$c_{\mathrm{g}}=1000\left(K+Q U_{\mathrm{P}}\right)$

where $K$ and $Q$ are constant values that depend on the stored product and $U_{\mathrm{P}}$ is the moisture content (\%) on a wet basis. 
The differential heat of sorption was estimated in each iteration step by applying Eq. (6) (Thorpe, 2001). This method was based on the Clapeyron equation and compares the vapor pressures of water in equilibrium with moist grain and free water.

$$
\begin{aligned}
h_{\mathrm{S}}= & h_{\mathrm{v}}\left(1+\frac{A \exp (-B U)}{(\theta+C)^{2}}(\theta+273.15)\right. \\
& \left.\times\left(-5+\frac{6800}{\theta+273.15}\right)\right)
\end{aligned}
$$

where $A, B$ and $C$ are constant values that depend on the stored product.

The equilibrium relative humidity (ERH) and the humidity ratio of the intergranular air for each section were also calculated in each iteration step. The ERH was obtained using Chung-Pfost equation, which is one of the equations approved by the ASAE (Brooker et al., 1992).

The value of $\mathrm{d} h_{\mathrm{v}} \mathrm{d} T_{\mathrm{a}}$ was considered equal to -2363 from Eq. (7), presented by Cengel and Boles, according to Thorpe (2001). This equation was obtained by fitting a linear equation to thermodynamic data given in standard textbooks and it gives values of latent heat from vaporization of water within a maximum error of $0.02 \%$ in the temperature range from 0 to $50^{\circ} \mathrm{C}$.

$h_{\mathrm{v}}=2501330-2363 T_{\mathrm{a}}$

The heat from oxidation of grain was considered equal to $15,778 \mathrm{~kJ} \mathrm{~s}^{-1} \mathrm{~m}^{-3}$ since the oxidation of $1 \mathrm{~kg}$ of grain substrate liberates $15,778 \mathrm{~kJ}$ of heat and forms $1.47 \mathrm{~kg}$ of carbon dioxide and $0.6 \mathrm{~kg}$ of water (Thorpe, 2001).

The porosity of bulk grain was also considered a constant value $(40 \%)$ based on Brooker et al. (1992). They reported that the intergranular void volume is $35-55 \%$ of the bulk grain volume for most product types. Therefore, considering this parameter as a constant value the model becomes simpler and does not affect the results significantly.

The density of intergranular air was calculated by using Eq. (8), presented by Alé (2001), in order to consider the altitude effects on this parameter.

$\rho_{\mathrm{a}}=\frac{352.8 P_{\text {atm }}}{101.325\left(T_{\text {aera }}+273.15\right)}$

where $T_{\text {aera }}$ is the aeration air temperature $\left({ }^{\circ} \mathrm{C}\right)$ and $P_{\text {atm }}$ is the barometric pressure $(\mathrm{kPa})$.

In our approach to developing a simpler model, the diffusion term and the rate of energy flowing into the bin by thermal conduction, used in the original model, were neglected. This procedure was based on some tests we conducted during the development of the software. Even when the fan was considered to be turned off, the simulation results were very similar whether or not these terms were considered. These observations can be explained due the low values associated with the effective diffusivity of moisture vapor through grain and due to the high insulation thermal coefficient of the bulk grain.
Another term observed in the original model that was not used in AERO was the differential of integral heat of wetting of grains with respect to temperature $\left(\partial H_{\mathrm{w}} / \partial T\right)$. According to Thorpe (2001), this term could be neglected because its value cannot be calculated accurately since its equation was obtained using a large number of differentiation functions with empirically fit data.

The velocity of the aeration air was estimated by Eq. (9) depending on the bin dimensions and on the required airflow rate:

$u_{\mathrm{a}}=\frac{q V}{S}$

where $u_{\mathrm{a}}$ is the velocity of aeration air $\left(\mathrm{m} \mathrm{s}^{-1}\right), V$ the bin volume $\left(\mathrm{m}^{3}\right), S$ the bin cross section area $\left(\mathrm{m}^{2}\right)$ and $q$ is the required airflow rate $\left(\mathrm{m}^{3} \mathrm{~s}^{-1} \mathrm{~m}^{-3}\right)$.

Finally, a method developed by Thompson (1972) was used to determine the rate of dry matter loss. An empirical equation was applied considering that the dry matter loss is time dependent (Eq. (10)).

$$
\frac{\mathrm{d} m_{\mathrm{s}}}{\mathrm{d} t}=\frac{\begin{array}{c}
14.72 \times 10^{-10}\left\{\exp \left(1.667 \times 10^{-6} t / M_{\mathrm{M}} M_{\mathrm{T}}\right)\right\} \\
+2.833 \times 10^{-9}
\end{array}}{M_{\mathrm{M}} M_{\mathrm{T}}}
$$

The terms $M_{\mathrm{M}}$ (moisture modifier) and $M_{\mathrm{T}}$ (temperature modifier) modify the grain conditions depending on its moisture content and temperature. $M_{\mathrm{T}}$ can be calculated by Eq. (11) (when temperature is lesser or equal to $15.5^{\circ} \mathrm{C}$ and moisture content is lesser or equal to $19 \%$ w.b.), 12 (when temperature is greater than $15.5^{\circ} \mathrm{C}$ and moisture content is between 19 and $28 \%$ w.b.) and 13 (when temperature is greater than $15.5^{\circ} \mathrm{C}$ and moisture content is greater or equal to $28 \%$ w.b.). The moisture modifier is obtained by Eq. (14).

$$
\begin{aligned}
M_{\mathrm{T}}= & 32.2 \exp (-0.1044 \theta-1.856) \\
M_{\mathrm{T}}= & 32.2 \exp (-0.1044 \theta-1.856) \\
& +\frac{U_{\mathrm{P}}-19}{100} \exp (0.0183 \theta-0.2847) \\
M_{\mathrm{T}}= & 32.2 \exp \left(-0.1044 M_{\mathrm{M}} M_{\mathrm{T}} \theta-1.856\right) \\
& +0.09 \exp (0.0183 \theta-0.2847) \\
M_{\mathrm{M}}= & 0.103\left(\exp \left(\frac{455}{(100 U)^{1.53}}\right)-0.845 U+1.558\right)
\end{aligned}
$$

The simpler model obtained has the advantages that its solution is easier to obtain and it saves computing resources.

\section{Results and discussion}

The software AERO was written in Java and is compatible with Windows, Linux and Mac. The simulation results can 


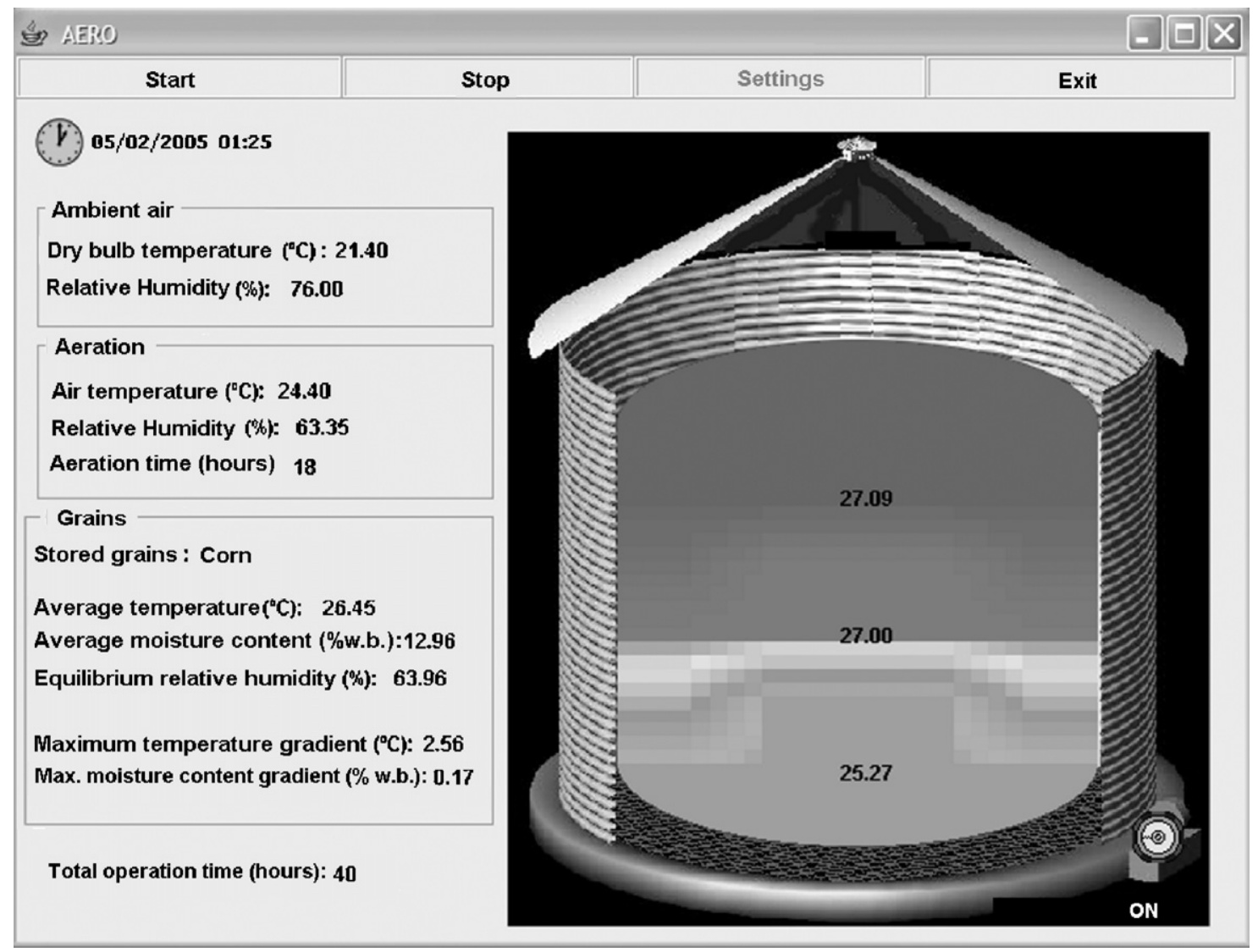

Fig. 2. Output data screen of AERO.

be viewed on the software screen (Fig. 2) and are also saved in electronic spreadsheets.

The simulation model results were verified against experimental data collected from January to August 2005 using a bin with a diameter of $2.6 \mathrm{~m}$ and a height of $1.5 \mathrm{~m}$, located at the Federal University of Viçosa (Brazil) and filled with maize. Figs. 3-5 show the graphical comparison of data for $100 \mathrm{~h}$ of aeration in June 2005, for the three evalu-

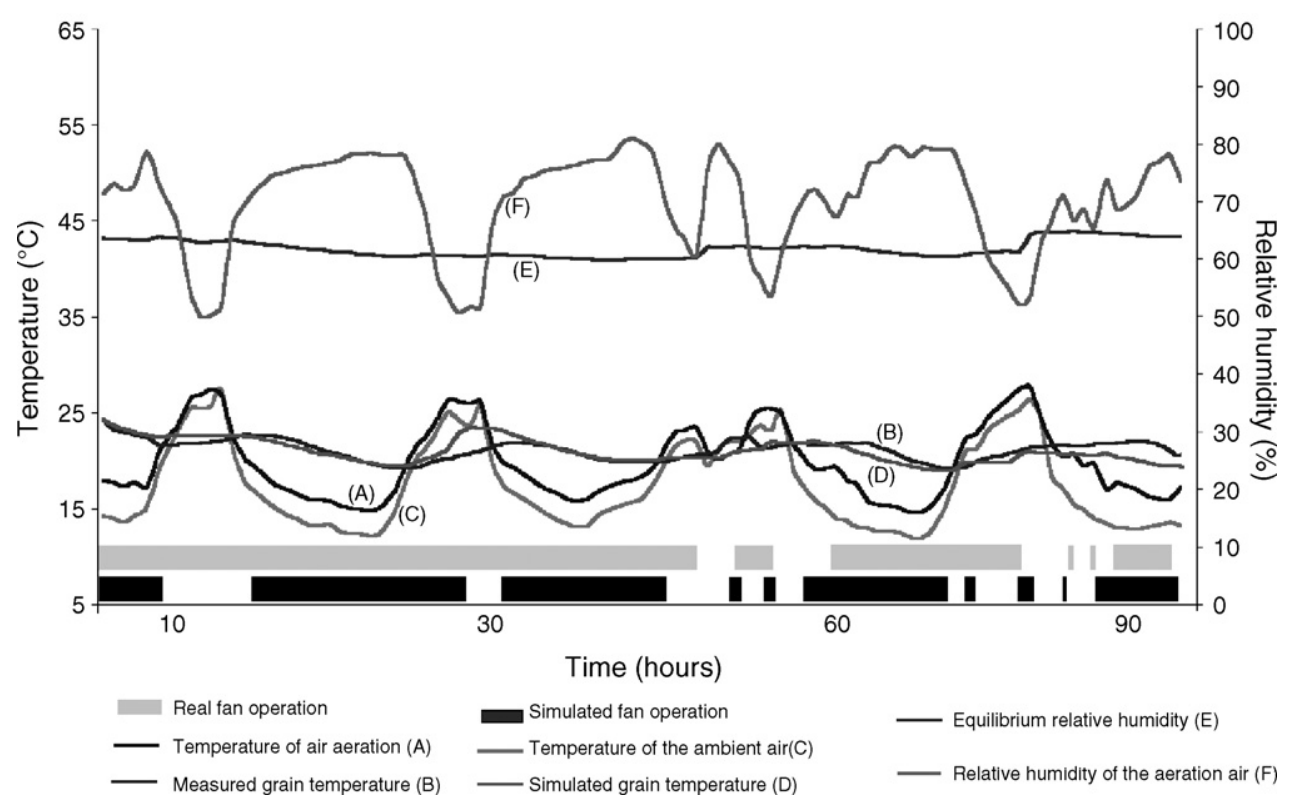

Fig. 3. Measured and simulated data profiles vs. time at the first bulk grain level for $100 \mathrm{~h}$ in June 2005 . 


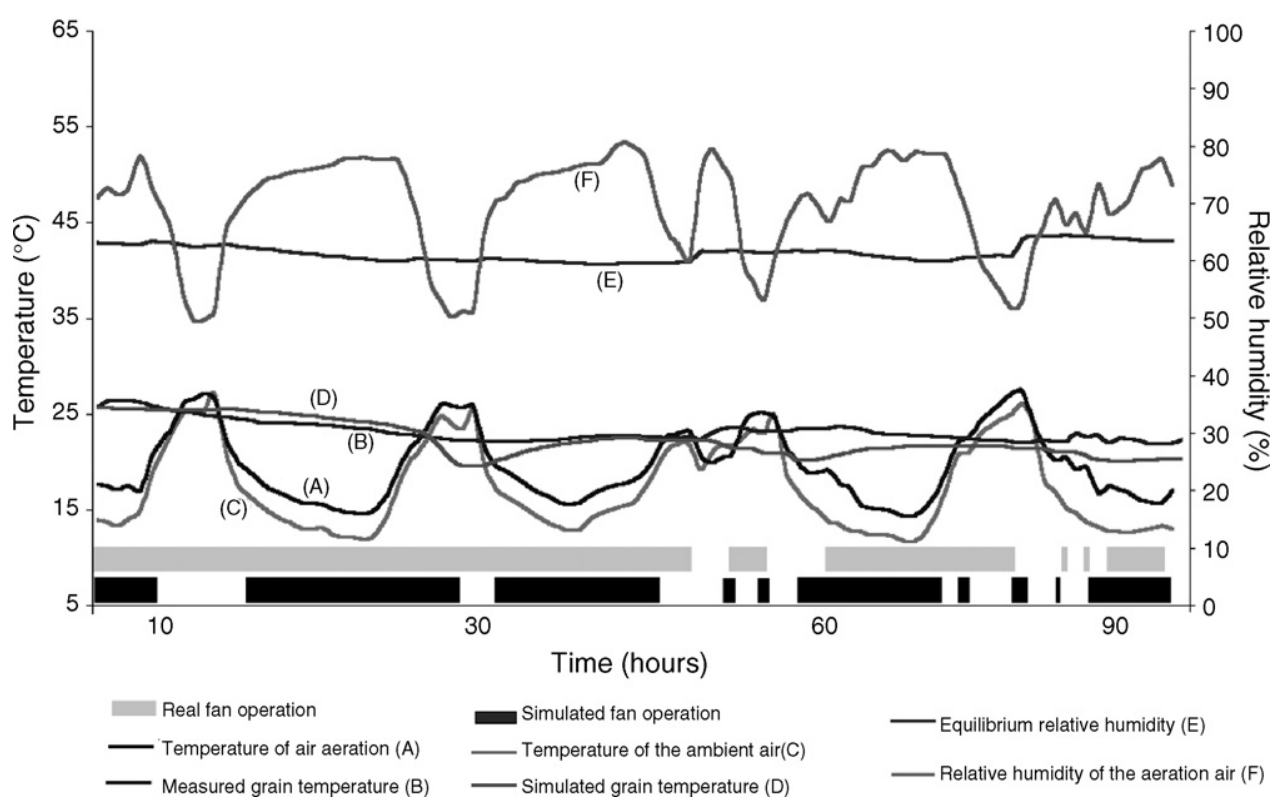

Fig. 4. Measured and simulated data profiles vs. time at the second bulk grain level for $100 \mathrm{~h}$ in June 2005 .

ated grain sections. The predicted temperatures were compared with the measured ones taken at three levels, monitored by DS1820 addressable temperature sensors from the 1 -Wire ${ }^{\mathrm{TM}}$ series. It is important to highlight that as the distance between nodes is reduced, the numerical solution becomes a better approximation. Although, only three levels were monitored, the simulation was performed using 15 sections. To compare the results, an average of each five simulated sections was used, characterizing each monitoring level. Also, if users choose a number of sections that results in a layer thickness greater than $0.5 \mathrm{~cm}$, they are advised that better results could be achieve if more sections are considered.

During the observed period, the average daytime temperature of the ambient air was $19^{\circ} \mathrm{C}$ and the average temperature of the night time ambient air was $13.5^{\circ} \mathrm{C}$. The average temperature of the aeration air was $21^{\circ} \mathrm{C}$ for the day period and $16.9^{\circ} \mathrm{C}$ for the night. The average relative humidity of the air aeration was $70 \%$. The maximum and the minimum relative humidity of aeration air observed in this period were 81.2 and $50 \%$, respectively. The average moisture content of the stored grain was $13.6 \%$ wet basis. Initially, the

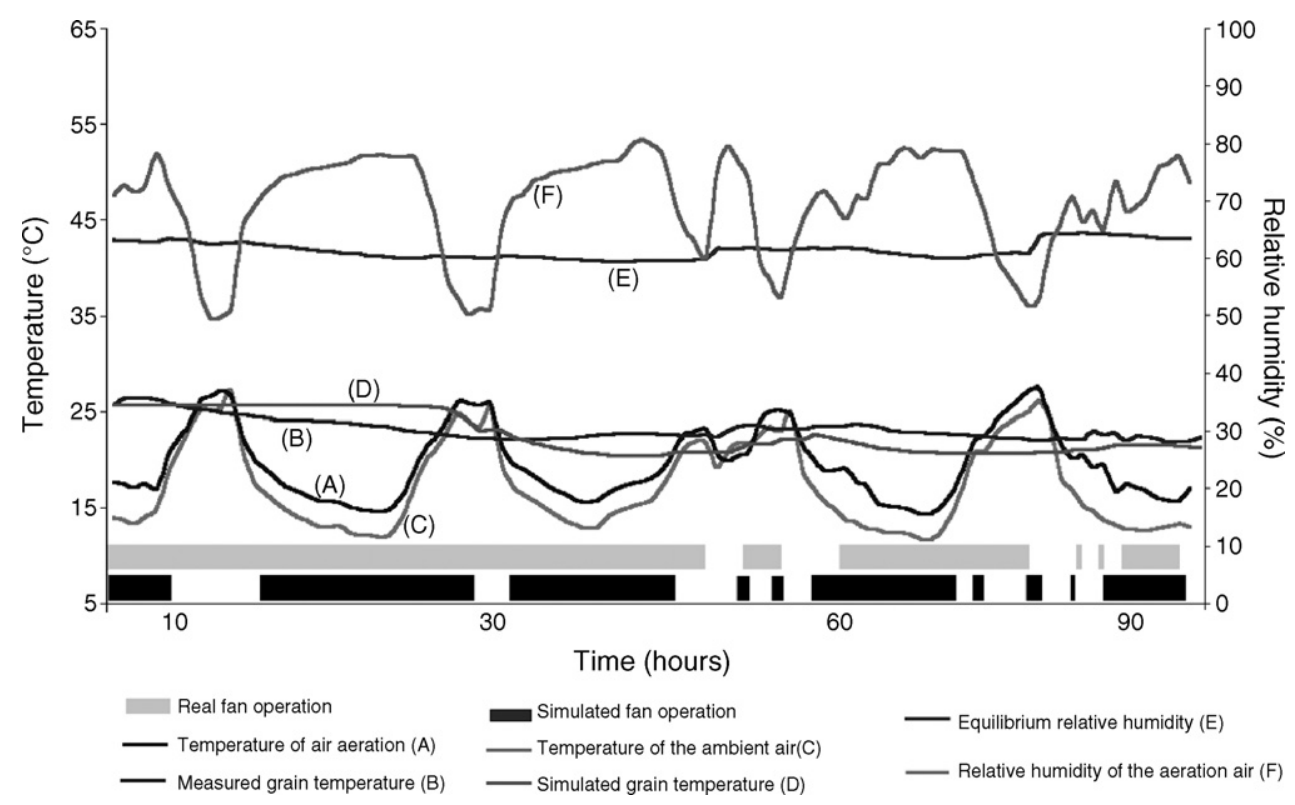

Fig. 5. Measured and simulated data profiles vs. time at the third bulk grain level for $100 \mathrm{~h}$ in June 2005 . 
temperature of the three bulk grain levels were 24.32, 25.7 and $25.88^{\circ} \mathrm{C}$, respectively. During the period observed in Figs. $3-5$, these temperatures dropped to $22,22.5$ and $22.7^{\circ} \mathrm{C}$, respectively.

The predicted results agree well with recorded data. From these results, it could be noted that the mathematical model gives a good prediction of the stored grain system for moments when the aeration system was turned on and turned off. Also, the simulated operation of the aeration system matches well during the times when the fan was on and off.

The maximum difference between measured and simulated temperatures was $3.2^{\circ} \mathrm{C}$ at the second bulk grain level. By using a larger bin, better results can be reached because the solar radiation and air convection influence will be smaller and the model will predict the real data better. During the day, higher temperatures were observed near the wall and the surface than those near the center of the bin. During the night, when the ambient temperatures dropped, the cooling process was more accentuated in these regions of the bin.

The results are strongly dependent on the control strategy used, which considered the relationships between the aeration air and the bulk grain conditions. The objective of the control strategy was to maintain the temperature gradient inside the bin smaller than $3{ }^{\circ} \mathrm{C}$ and cool the bulk grain whenever possible. The predicted moisture content was used in the control strategy to prevent the possibility of grain kernels, near the air inlet, to be excessively dried or dampened. These objectives guarantee safe storage conditions in tropical and subtropical regions in which accentuated daily and seasonal temperature fluctuations occur and where suitable cooling could not be achieved. In these regions, the aeration system should be used as a preventive tool and its success will depend on additional care to store the grain dry and clean.

\section{Conclusion}

The mathematical model proposed by Thorpe (1997) and presented in more details by Thorpe (2001), can be successfully used with some modifications, suggested in this research, for predicting the complex changes in stored grain systems under various conditions and with the aeration system turned on or turned off. This will help students, con- sultants, teachers and other storage professionals predict the behavior of aeration systems.

\section{References}

Alagusundaran, K., Jayas, D.S., White, N.D.G., Muir, W.E., 1990. Finite difference model of three-dimensional heat transfer in grain bins. Can. Agric. Eng. 32, 315-321.

Alé, J.F., 2001. Sistemas de ventilação industrial-ventiladores. Departamento de Engenharia Mecânica e Mecatrônica, LSFM, PUCRS (in Portuguese).

Andrade, E.T., 2001. Simulação da variação de temperatura em milho armazenado em silo metálico. Viçosa, Minas Gerais: Imprensa Universitária, Universidade Federal de Viçosa, Tese de doutorado em Engenharia Agrícola 174 pp. (in Portuguese with English abstract).

Brooker, D.B., Bakker-Arkema, F.W., Hall, C.W., 1992. Drying and storage of grains and oilseeds. AVI Book, USA, $450 \mathrm{pp}$.

Canchun, J., Da-Wen, S.E., Chongwen, C., 2001. Computer simulation of temperature changes in a wheat storage bin. J. Stored Prod. Res. 37, 165-167.

Davidson, M.R., 1986. Natural convection of gas/vapor mixtures in a porous medium. Int. J. Heat Mass Transfer 29, 1371-1381.

Devilla, I.A., 2002. Simulação de deterioração e de distribuição de temperatura e umidade em uma massa de grãos armazenados em silos com aeração. Viçosa, Minas Gerais, Imprensa Universitária, Universidade Federal de Viçosa, Tese de doutorado em Engenharia Agrícola 84 pp. (in Portuguese with English abstract).

Muir, W.E., Fraser, B.M., Sinha, R.N., 1980. Simulation model of twodimensional heat transfer in controlled atnosfhere grain bins. Can. Agric. Eng. 12, 21-24.

Navarro, S., Noyes, R.T., 2001. The mechanics and physics of modern grain aeration management. CRC Press, Boca Raton, 647 p.

Sinício, R., Muir, W.E., Jayas, D.S., 1997. Sensitivity analysis of a mathematical model to simulate aeration of wheat stored in Brazil. Postharvest Biol. Technol. 11, 107-122.

Thompson, T.L., 1972. Temporary storage of high-moisture shelled corn using continuous aeration. Transactions of the ASAE. St. Joseph, MI, vol. 15 , no. 2 , pp. 333-337.

Thorpe, G.R., Elder, W.B., 1982. The effects of aeration on the persistence of chemical pesticides applied to bulk stored grain. J. Stored Products Res. 18, 103-114.

Thorpe, G.R., 1997. Modelling ecosystems in ventilated conical bottomed farm grain silos. Ecol. Modell. 94, 255-286.

Thorpe, G.R., 2001. Physical basis of aeration. In: Navarro, S., Noyes, R.T. (Eds.), The Mechanics and Physics of Modern Grain Aeration Management. CRC Press, Boca Raton, pp. 125-194, Chapter 4.

White, G.G., 1988. Temperature changes in bulk stored wheat in subtropical Australia. J. Stored Products Res. 24, 5-11.

Wilson, S.G., 1988. Simulation of thermal and moisture boundarylayers during aeration of cereal grain. Mathematics Comp. Simul. 30, 181-188. 